\section{Cuidado, "cavalo batizado" e crítica da conduta profissional pelo paciente-cidadão hospitalizado no Nordeste brasileiro}

\author{
Patients' complaints of verbal abuse by \\ health professionals during hospital care in \\ Northeast Brazil
}

\author{
1 Programa de Pós- \\ Graduação em Saúde \\ Coletiva, Universidade de \\ Fortaleza, Fortaleza, Brasil. \\ 2 Harvard Medical School, \\ Harvard University, \\ Boston, U.S.A. \\ 3 Núcleo de Humanização na \\ Atenção e Gestão em Saúde, \\ Secretaria da Saúde do \\ Estado do Ceará, Fortaleza, \\ Brasil. \\ Correspondência \\ M. K. Nations \\ Departament of Social \\ Medicine, Harvard Medical \\ School, Harvard University, \\ 641 Huntington Avenue, \\ Boston, Massachusetts, \\ U.S.A 02115. \\ Marilyn_Nations@hms. \\ harvard.edu
}

\begin{abstract}
The current anthropological study focuses on the assessment by patients/citizens concerning the conduct of health professionals in a public general hospital in Fortaleza, Ceará State, Brazil. From January to July 2005 we tracked 13 key informants during hospitalization and analyzed their narratives of the experience. According to our observations, patients develop definite opinions of the caregivers' gestures and expressions during the entire process. In the health professionals, patients appreciate the human ability to express affect, to talk, and to include them in clinical decisions, above and beyond the professionals' technical skills. Patients criticize aloof, cold, and rude attitudes by health professionals, whom patients compare metaphorically to "human quadrupeds". They recommend an affective, empathetic, and ethical approach and clinical communications backed by straight talk, friendly conversation, and respect for daily customs related to life in Northeast Brazil. We contend that this legitimate and critical voice of the patient/citizen provides valuable clues for transforming professional conduct, rehabilitating patients' morale, and building a humane hospital within a context of social inequalities.
\end{abstract}

Physician-Patient Relations; Humanization of Assistance; Delivery of Health Care
Marilyn K. Nations 1,2

Annatália Meneses de Amorim Gomes 3

\section{Introdução}

A relação terapêutica exige competência em cuidar pelo profissional e, simultaneamente, a autonomia e o "empoderamento" do paciente 1,2. As habilidades relacionais fortificam o vínculo entre ambos e a co-responsabilidade. A prática clínica, entretanto, é atravessada pela precária estrutura, gestão centralizadora, difícil acesso, desorganização, tecnicismo e poder hegemônico da Biomedicina 3 .

A mudança na conduta profissional está pautada na inclusão da subjetividade e das raízes socioculturais do paciente 4 . Isso porque o médico trata a patologia da doença, enquanto o paciente sofre a experiência de adoecer, expressa em formas específicas de pensar e agir 4 .

A formação acadêmica, todavia, não prepara o profissional para escutar os significados e sentidos do paciente, comprometendo a qualidade do cuidado 5,6. É preciso uma "tecnologia da interação humana” que permita a visão política da cidadania 7 , o pensamento problematizador ${ }^{8} \mathrm{e}$ a ética do cuidado ${ }^{9}$. Maior eqüidade de poder na relação clínica exige integrar diferentes conhecimentos, respeitar a singularidade do paciente $\mathrm{e}$ promover o protagonismo 10,11, tornando o trabalho vivo e criativo 2 .

Objetivamos analisar a relação do cuidado sob a óptica do paciente internado em hospital público, identificando as competências julgadas indispensáveis na conduta do profissional. 


\section{Métodos}

De janeiro a julho de 2005, esta pesquisa antropológica foi realizada num hospital geral público, selecionado aleatoriamente entre as duas instituições existentes em Fortaleza (população de 2,2 milhões de habitantes), Ceará, no Nordeste brasileiro, contexto marcado pela crescente desigualdade econômica e segregação social; de 1991 a 2000, o distanciamento entre os $10 \%$ mais ricos e os $40 \%$ mais pobres aumentou de $13,3 \%$ para $18,7 \% 12$.

Participaram 13 pacientes, quatro homens e sete mulheres entre 16 e 93 anos, selecionados aleatoriamente: (1) identificação na chegada; (2) escolha do primeiro na fila do atendimento; (3) inclusão de pelo menos um de cada setor (Clínica Médico-Cirúrgica, Gineco-Obstétrica, Neonatologia e Emergência); (4) tomada de casos diversificados. Foram excluídos pacientes com transtorno psíquico e $<16$ anos. A maioria (61,5\%) é casada; 23,1\% são solteiros; e 15,4\%, separados. Na periferia de Fortaleza, reside grande parte $(84,6 \%)$, com $15,4 \%$ em outros municípios do Estado. Quase a metade (46,3\%) é analfabeta ou não completou o primeiro grau; 7,7\% terminaram o primeiro grau; e 46,1\% estão cursando ou concluíram o segundo grau. A maior parte $(53,8 \%)$ é inativa economicamente. Mais de dois terços $(77 \%)$ foram internados pela primeira vez; e $23 \%$, por 2 a 5 vezes.

Para situar os pacientes no seu universo de significação 13 e captar a experiência vivida da internação, criamos uma combinação de técnicas que nomeamos "O Percurso do Paciente". Durante os primeiros três meses, utilizamos a observação livre. Subseqüentemente, os pacientes foram acompanhados desde a entrada até a alta hospitalar. A periodicidade do acompanhamento, de 7 horas a 60 dias, dependeu da permanência no hospital. O menor tempo seguido (7 horas) foi uma biopsia uterina na clínica ginecológica. Percursos que duraram $<7$ dias foram: um parto normal (dois dias), uma cirurgia estética vaginal (três dias), uma retirada de nódulo no dedo do pé (três dias), uma cirurgia da tireóide (cinco dias) e uma pré-eclâmpsia (cinco dias). Durante duas semanas, acompanhamos um paciente com dores ósseas na clínica reumatológica (dez dias), um parto de alto risco na Casa da Gestante (12 dias) e uma cirurgia bariátrica (14 dias). Por $>1$ mês, seguimos um paciente com leishmaniose cutânea (30 dias), um parto prematuro no Projeto Mãe Canguru (39 dias) e uma biopsia pulmonar (45 dias). Durante dois meses, foi acompanhada uma histerectomia.

Entrevistas etnográficas foram mescladas com narrativas 14 de momentos vividos e obser- vação-participante. Ocorriam de forma flexível, com algumas situações favorecendo uma técnica ou a outra. Foram guiadas, mas não limitadas, por questões norteadoras: (1) conte-me como está sendo a sua permanência no hospital; (2) descreva como foi para você ficar internado; (3) descreva algum evento que o fez se sentir melhor no hospital; (4) relembrando desde a chegada no hospital, conte-me o que poderia ser feito para tornar a sua convivência mais humana; (5) tem algo mais a dizer sobre a sua passagem pelo hospital? Essas entrevistas prolongaram-se durante toda a internação; a freqüência da coleta foi determinada pelo princípio de saturação 15 . Com o aparecimento de novidades - aquilo que o paciente destacava - os intervalos entre as entrevistas encurtavam. Em momentos oportunos, os pacientes foram incentivados a narrarem livremente a própria versão dos acontecimentos no instante em que ocorriam. Essa coleta prospectiva, na presença das pesquisadoras, principiava com uma frase ou pergunta desencadeadora: "conte-me o que está acontecendo", "como você está se sentindo agora?”, situando o paciente em contato com seus sentidos. Com o aumento da confiança nas pesquisadoras, as narrativas aconteciam espontaneamente. Finalmente, a observação-participante foi utilizada para mergulhar na realidade hospitalar, experienciando os acontecimentos junto com o paciente. As entrevistas e narrativas foram gravadas e transcritas, produzindo um texto numeroso de 331 páginas, espaço simples.

Os dados foram analisados segundo a Análise de Conteúdo 16. Após leituras repetidas das transcrições, emergiram 225 unidades de significação, agrupadas e codificadas em cinco temáticas, das quais, três - competência humana, participação do paciente e competência técnica -, relevantes à relação terapêutica, foram consideradas; 138 apreciações dos 13 pacientes sobre a competência profissional foram identificadas. As outras duas temáticas, estrutura/funcionamento dos serviços e imagem hospitalar, foram excluídas desta análise. A interpretação transcorreu à luz da antropologia interpretativa.

O sigilo e o anonimato dos informantes foi garantido; e o Termo de Consentimento Livre e Esclarecido, assinado, de acordo com Resolução $n^{o}$. 196/96 do CNS/Ministério da Saúde, Brasil.

\section{Resultados}

\section{O que importa}

A habilidade do profissional de saúde mais relevante na óptica do paciente internado é a 
competência humana, referida em $60,2 \%$ das 138 apreciações. Saber cuidar da pessoa, não somente da doença, é crucial. Competência em ser afetivo, hábil em conversar e incluir o paciente na tomada de decisão constituem requisitos fundamentais. Embora menos freqüente (39,8\%), também é importante a competência técnica em realizar procedimentos (Tabela 1). Apesar da diversificação dos casos, as fragilidades relacionais desveladas se aplicam a todos os 13 casos acompanhados.

\section{Competência humana em ser afetivo}

O paciente destaca como o cerne do cuidado humanizado a relação com o profissional (27,5\% das apreciações). Avalia pelo grau de proximidade que o cuidador estabelece, ou não, com o assistido. Julga um trato distante e frio como desligamento afetivo. Saber aproximar-se e interagir delicadamente é a habilidade mais referida, diferenciando um profissional humano de outro "bravo, ignorante, ruim (...) que não é bondoso, não tem coração ou até um cavalo batizado" pessoa bruta que dá coice em quem se aproxima; a única diferença do animal cavalo é ser batizado na igreja quando o é. Essa conduta desumanizada choca-se com a expectativa de ser tratado como gente. Pacientes esperam uma ligação carinhosa, empática e honrada.

\section{- Ligação carinhosa}

No encontro clínico, é valorizada a troca afetiva. Um laço de amizade entre o profissional e o paciente é tão importante quanto elos com amigos na vida cotidiana. No círculo de amizade, o outro não é alguém estranho, invejoso ou maldoso, mas aquele em quem você pode confiar, comparti- lhando segredos e ternura igual a um amigo do peito, amigo verdadeiro. A liga que os une é o amor.

Observamos, contudo, poucos gestos de carinho - beijo no rosto, toquezinho nas costas e barriga, cafuné, dar as mãos etc., com uma exceção. Após dois anos à espera da cirurgia para reduzir o estômago, Mário, 42 anos, ficou alegre, pois seu médico festejou junto o fim do sofrimento pela obesidade.

Estabelecer um elo afetivo exige um cuidado genuíno: "ele é delicado, atencioso, cuidadoso e cauteloso". Trata o paciente com "educação, compreensão e respeito, deixa à vontade". O profissional robotizado é percebido: "é fechado, calado, desligado (...) só trabalha por obrigação (...) só o ser profissional, sem sentimentos". Um motorista de ambulância reclama da autoridade medonha dos atendentes: "é preciso que esse pessoal goste deles mesmos para dar amor ao outro. A gente quase sempre é humilhado!" O olhar acolhedor do profissional é decisivo. Sem ele, o procedimento é julgado inadequado: "o exame não prestou (...) nem olhou para minha cara!"

A liga carinhosa é mais forte entre os companheiros da enfermaria, que rapidamente se tornam amigos do peito, repartindo objetos, cuidados, conselhos e afetos. Observamos cenas fraternas no cotidiano hospitalar: um visitante penteando o cabelo de um paciente idoso, e dois homens debilitados, em camas próximas, acariciando um ao outro.

\section{- Elo de empatia}

Para o paciente, é essencial aflorar elos de empatia. Acontece quando o profissional percebe " $a$ necessidade da gente na própria pele”, demonstra compaixão e preocupa-se com o bem-estar do

Freqüência de competências do profissional da saúde valorizadas pelo paciente no hospital público. Fortaleza, Ceará, Brasil, 2006. ( $N=138$ apreciações de 13 pacientes).

\begin{tabular}{lcc}
\hline Competência do profissional da saúde & $\mathbf{n}$ & $\%$ \\
\hline Humana & 38 & 27,5 \\
Atitudes e habilidades de ser afetivo com o paciente & 28 & 20,2 \\
Atitudes e habilidades de conversar com o paciente & 17 & 12,3 \\
Atitudes e habilidades de incluir o paciente em decisões clínicas & 83 & 60,2 \\
Subtotal & 55 & 39,8 \\
Técnica & 138 & 100,0 \\
Atitudes e habilidades de realizar procedimentos clínicos & \\
Total de apreciações & \\
\hline
\end{tabular}


paciente. O Sr. Mano, 93 anos, internado há 35 dias para tratar sua ferida braba (leishmaniose cutânea), criou laços empáticos com o médico que cuidadosamente trocou seu curativo: " $F i$ quei amigo dele, como se fosse de casa (...) É gente boa!".

A dificuldade de sentir o sofrimento do paciente inibe uma relação solidária. É desatenção, descortesia e descaso não ver a pessoa no paciente, como Júlia, 16 anos, após seu parto normal. A enfermeira a deixou desprovida de absorventes e calcinhas. A jovem mãe capengava pelo corredor, sua bata aberta atrás, expondo um lençol dobrado que ela segurava entre as pernas (para conter o sangue), enquanto carregava o seu bebê.

\section{- Ligação que "honra"}

Embora pacientes destaquem que o cuidador competente respeita a dignidade humana, predominaram exemplos de familiares e não profissionais. Por ser um filho de Deus, acreditam merecer um trato digno de gente! Portanto, têm a expectativa da eqüidade, não distinção de classe social, cor, raça, etnia ou credo religioso. O profissional não pode "querer ser mais do que a gente (...) diante de Deus todos somos iguais!" Se essa dignidade é nutrida, o cuidador é admirado.

Gestos que afirmam a singularidade do paciente o valorizam como ser humano: cobrir a gestante com um lençol, respeitar os horários de sono e facilitar visitas. Atitudes honradas respeitam as crenças religiosas, incentivando a leitura bíblica, reza do terço, visitas de pastores etc.

O desrespeito é sentido quando o profissional desmoraliza, rebaixa, esnoba e o ignora: "você fala, mas ele não responde (...) é como se a gente não existisse". Sente-se inferiorizado pelo policial armado que revista seus pertences. Despreza-o quando a faxineira retira as pulseiras de identificação dos bebês afixadas pelas mães na imagem de Nossa Senhora na entrada da UTI neonatal, pedindo a salvação dos seus recémnascidos.

A conduta desqualificadora leva o paciente a uma percepção pejorativa de si mesmo, "eu não era nada ali dentro (...) a única coisa que importava era o prontuário". Compara-se a algo sujo ou objeto sem vida. Amélia, 25 anos, gestante com pré-eclâmpsia, sentiu-se "como se fosse um pano de chão, pisada por todo mundo" quando a enfermeira confiscou sua carteira de identidade e negou o contato com a família. Outra se compara a um pedaço de carne: "corta a gente (...) bota aquela carne ali, leva pra acolá e pronto. Parece um açougue!'

\section{Competência humana em conversar}

Em segundo lugar (20,2\% das apreciações), o paciente valoriza o profissional que conversa com ele e sua rede social. É priorizada uma comunicação informal: uma "fala esclarecedora, conversa amiga, conversa aberta, conversa jogada fora e conversa sincera".

\section{- Fala esclarecedora}

O paciente espera ser informado, minimizando o medo do estranho mundo hospitalar. Sente-se uma barata tonta, perambulando pelos corredores, desorientada em busca de um esconderijo seguro. Revela a importância das orientações, como relata uma gestante de alto risco: "eu imaginava chegar aqui (...) ter um profissional para conversar antes de entrar na sala de cirurgia, explicar tudo para mim [tenha calma (...) não vai doer (...) é um cortezinho (...) é uma coisa]". Essa fala esclarecedora não se limita à patologia, mas engloba diversos assuntos: o nome do médico, o efeito da anestesia, local da capela e as chances de curar-se.

Não basta transmitir a informação, é preciso esclarecer o sentido das palavras para que $a$ gente entenda. $\mathrm{O}$ uso do jargão técnico dificulta o entendimento. Sr. Cláudio, 76 anos, aguardava angustiado, há dias, pela confirmação de um tumor maligno: "examina, mas não explica (...) porque o médico disse uma coisa 'medicinal' (...) a gente não entende essas coisas, né? Só eles que entendem tudo".

A informação deveria ser transmitida livremente, não guardada, negada ou encoberta. Observamos, no entanto, na emergência obstétrica, uma jovem em trabalho de parto, há mais de oito horas, sem saber se seria transferida e para onde. O marido foi impedido de acompanhá-la pelo segurança, que o retirou à força. Ninguém informou o seu destino. Conseguir informação da central, uma sala de vidro, fechada e climatizada, é possível somente através de um microfone.

Todos os profissionais deveriam prestar informações. O leigo não distingue quem sabe o quê; ele procura dicas para navegar dentro da instituição. Vimos duas filhas apelando por notícias sobre a morte inesperada da mãe de 52 anos. De acordo com a rotina do óbito, a assistente social é encarregada de dar a má notícia do falecimento, não a equipe que lhe operou da tireóide. Aquele profissional que não informa é desqualificado como quem não sabe de nada.

A falta de informação provoca insegurança. A única saída é entregar-se nas mãos de Deus: "Ele é quem sabe". Mário, no aguardo dos exames 
para sua cirurgia, desabafa: "foi a ansiedade desse exame, a espera (...). A gente bota muita coisa na cabeça, se sente perdido". O desespero por informação levou outra a implorar clareza: "apelo que deixem tudo mais claro (...) têm muitas mulheres mal informadas!"

\section{- Conversa amiga}

Na conversa amiga, o profissional chama o paciente pelo nome, demonstra interesse, conhece o seu problema e escuta o que ele tem a dizer. Estabelece uma interação humana com os sujeitos: "Como você está? O que está acontecendo?" Evita a impessoalidade, cumprimentos formais e perguntas dirigidas que induzem respostas automáticas, pois sequer propiciam o diálogo: “Tá tudo bem? Dormiu bem? Já se alimentou?"

Tal como ocorre entre amigos, essa fala incentiva, encoraja e dá segurança. Maria, 55 anos, ressalta sua conversa amiga com a médica durante um exame invasivo: "fique calma, tudo vai dar certo, não se preocupe, farei bem rápido, devagar, com cuidado (...). Ei, olhe para mim, vai passar, eu sei que está doendo, mas vai passar". Outra se sentiu segura, quando uma enfermeira pegou a sua mão no centro cirúrgico e exclamou: "olha, tá tudo bem, Deus está com você, e nós estamos entre os amigos".

A fala hostil ou brutal, que reprova, ironiza e agride, inibe a conversa amiga. Enquanto sofre dores do parto, uma enfermeira censura a gestante sarcasticamente: "aqui não tem nenhuma criança, não! (...) Você não é marinheiro de primeira viagem, não!" O profissional gritou com o Sr. Mano, 93 anos: "você é muito frouxo, não prestava para ser mulher, não!". Tais expressões produzem sentidos de rejeição, reforçando desigualdades na relação.

\section{- Conversa de "peito aberto"}

O profissional competente conversa abertamente, sem amarrar-se em assunto predefinido, deixando todos à vontade: "aquilo que a gente vê e sente pode falar, ajuda $100 \%$ na recuperação". Aproxima-se do paciente com o peito aberto, disponível a escutar, sem julgar o mérito ou impor seu pensamento: "não rebate o que a gente diz $e$ não dá sua opinião”. É uma fala acolhedora, que estimula o paciente a contar sua história de vida, pois "basta uma palavra, e a gente se sente motivada!"

Na fala fechada, ao contrário, o profissional fica de cara amarrada, rígida e tensa, sem abertura para dialogar. Há longo silêncio ou expressão monossilábica: vire, cuspa, tome, te vira, comunicando a indisponibilidade para interagir ou responsabilizar-se pelo outro. Elvira, 50 anos, indigna-se com o atendimento médico: "ele é muito fechado, fica calado (...) só examina e vai embora. Disse assim: tá aqui seu exame, passe numa farmácia e pegue seu remédio, aí volte em dois meses!"

\section{- Conversa "jogada fora"}

Pacientes valorizam uma conversação agradável, despretensiosa, bem-humorada e sem objetivo definido. A conversa jogada fora é um bate-papo descontraído, além do discurso técnico, monótono e sério, trazendo um ar de leveza à situação de dor e sofrimento. Esse papo legal acontece num clima de informalidade, como entre amigos de bar. Antes, durante e depois dos procedimentos, ajuda a relaxar, distrair e esquecer o momento doloroso. São falas da política, da novela, do jogo de futebol, da chuva no interior, dos filhos e histórias de vida. Em momentos tensos, o profissional competente alivia a preocupação, rindo, brincando e soltando piadas. Sônia nunca se esqueceu quando o seu bebê nasceu, e o obstetra brincou: "é um garotão (...). Estou vendo os sacos balançando!" E continuou cantando uma música carnavalesca: "balança o saco de confete e serpentina!"

\section{- Conversa sincera}

O caráter ético na comunicação é de suma importância, pois o bom cuidador é "igual a um padre que tem discrição”. Fala com sinceridade: "diz diretamente o diagnóstico para o paciente". A omissão de informação provoca desconfiança. Se o discurso do profissional é indefinido, efusivo ou contraditório, o paciente suspeita que está sendo intencionalmente enrolado. Elvira, 50 anos, internada para uma biopsia uterina, sentese traída pela ginecologista, que não revelou a verdade, enganando as mulheres. A médica não indica a cirurgia e a deixa angustiada: "por mais que a médica quisesse me explicar o porquê de não ter feito logo a cirurgia, eu não entendi (...) por que foi tirando aos poucos?" Devido à superlotação e espera de oito horas para se internar, outra paciente narrou sua descrença: "dizem que o leito está ocupado, que tá limpando, tá arrumando (...) só iludindo a gente!"

\section{Competência humana em incluir o paciente}

Incluir o paciente nas decisões clínicas é uma habilidade valorizada, embora com pouca freqüência (12,3\% das apreciações). Participar plenamente, questionar procedimentos terapêuticos, recusar cuidados e ter próximo os familiares são direitos admirados. É preciso o consentimen- 
to do paciente para realizar o protocolo e não executá-lo contra a sua vontade. O obstetra deveria explicar o "que a gestante precisa fazer para facilitar o parto e a participação no nascimento”.

O paciente desconfia do profissional ao sentir-se excluído. Embora o Sr. Cláudio, 67 anos, internado para uma biopsia pulmonar, não pudesse opinar sobre o seu tratamento, vigiava a enfermeira e o número de tubos de soro infundidos. Uma diabética, 60 anos, não foi consultada sobre a amputação do dedo do pé; amedrontada, procurou outro cirurgião com quem decidisse junto.

\section{Competência técnica em realizar procedimentos clínicos}

Embora o paciente valorize a capacitação técnica do profissional (39,8\% das apreciações), o faz atrás da competência humana $(60,2 \%$ das apreciações). As habilidades técnicas não são somente mecanicistas, pois consistem em aspectos subjetivos do fazer profissional. É insuficiente suprir as necessidades cotidianas do paciente: dar banho, servir comida, trocar curativo, mudar a posição na cama ou aplicar a injeção na hora certa. Ele aprecia como tais procedimentos são feitos e o impacto no seu bem-estar. Ser prestativo, realizar tarefas com gentileza e delicadeza, sem causar danos, é a marca de um profissional tecnicamente proficiente.

\section{- Ser prestativo}

Ser prestativo implica ter interesse e disponibilidade para cuidar. Essa prontidão para agir é crucial nas emergências e situações estressantes. O profissional "prestativo é sempre pertinho (...) ajudando quando a pessoa necessita (...) com sua atenção voltada para todos". Ele acompanha, de instante em instante, o paciente, o centro das suas atenções, independentemente do tipo ou grau de enfermidade. Quem é prestativo toca o paciente, é pontual e olha nos olhos: "verifica sinais de pressão, temperatura, pulso, olha o soro (...) acompanha a gente (...) fica ao lado no momento do parto (...) faz os procedimentos na hora certa (...) dá apoio quando alguém chora".

Esse profissional prestativo foi raro nas narrativas. Ouvimos queixas do funcionário ausente, indiferente e desligado. Ausentar-se emocionalmente, estar nem aí para o paciente é visto com desgosto. Uma enfermeira na sala de pré-parto ignora a gestante: “não liga (...) fica na dela (...) não se aproxima para ajudar, conversa em rodinhas enquanto precisamos de cuidados (...) passa de um lado pro outro sem dar atenção". Um técnico de radiografia desatencioso assiste à televisão enquanto realiza o exame.

\section{- Fazer delicado}

O toque suave no corpo e cuidados que minimizam a dor são apreciados. O profissional educado age com delicadeza, gentileza e cortesia em todos os momentos: realizar exames, trocar curativos, aplicar injeção e entregar a bandeja de alimentação.

Toda ação com bravura, rancor e violência é reprovada como maus-tratos em represália ao paciente. Aline foi agredida pelo obstetra no exame pré-parto: "eu via o rancor na cara dele. Só por que eu me encolhi (deu uma dor de contração) na hora que ele botou o aparelho para escutar o coração do bebê. Então, ele disse: - Eu não vou mais fazer esse exame, não! Mulher, você não deixa eu ajudar, agora agüente as conseqüências!' Exemplos de trato bruto são explicitados: aplicar injeção com força, servir comida com raiva e fazer tricotomia brusca. Uma senhora reclama que o maqueiro a conduzia pelos corredores com movimentos violentos, fazendo-a sentir-se desprotegida "apesar de estar sendo levada por aquele homem tão forte (...) poderia ser mais delicado!"

\section{- Fazer sem prejuízo}

O agir habilidoso é aquele que não causa danos e resguarda a segurança. Todo o esforço para cumprir o protocolo científico é insuficiente se o paciente for prejudicado na intervenção. A enfermeira aplica uma injeção com a medicação prescrita, agulha descartável, no local indicado, mas, se deixar uma marca roxa no braço, é julgada como despreparada. O dano é tatuado como prova do prejuízo no corpo e na memória: o edema, a cicatriz, a marca, a dor e o inchaço. Edna, 21 anos, critica a habilidade técnica do anestesista pelo número de furadas na aplicação da anestesia: " $a i$, eu não sei (...) não entendo a anestesia (...) mas será que ele precisava me perfurar três vezes?"

O aprendiz, ou estudante, sem prática clínica, prejudica mais facilmente. Faz medo quando alunos em treinamento atuam no serviço. Suzana, 52 anos, espantou-se ao descobrir seu cirurgião aprendiz, pois já tinha sido agulhada por estudantes, 16 vezes, numa biopsia de tireóide.

Para defender-se contra os danos, o paciente vigia o profissional, ficando de olho nos mínimos detalhes, sobretudo quando há risco de vida. Cláudio, 67 anos, queria um espelho no centro cirúrgico para acompanhar sua operação. Amélia, professora, 25 anos, desejava ver o rosto do seu recém-nascido com medo de alguém trocar o bebê. Um informante denunciou "os maus-tratos" hospitalares, mostrando-nos um congelador com corpos de recém-nascidos mortos, embrulhados e congelados no velório. 


\section{Discussão}

A experiência vivida de internação no hospital público, em Fortaleza, Ceará, é marcada pelo sofrimento humano e fragilidades relacionais com o profissional; reflete no cuidar a pobreza e a desigualdade social predominante no Nordeste brasileiro. Para que ocorra essa violência institucional, não parecem relevantes as diferentes patologias, os serviços consultados, os procedimentos requeridos ou o tempo de estada no hospital. Todos os pacientes acompanhados, em momento de vulnerabilidade, são isolados, impedidos de entrar com seus pertences e afastados do seu cotidiano e referenciais - casa, família, amigos, trabalho e padrões culturais. São submetidos à imposição autoritária de normas, regras e poder hegemônico, como em outros hospitais públicos do Brasil 3,17.

Além da doença, o paciente é discriminado pelo estigma; é "coisificado" 18 ou reduzido à condição de objeto: pano de chão, pedaço de carne e barata tonta. Chauí 19 (p. 336) nos lembra que pessoas tratadas como coisas produzem violência: "o exercício da força física e da coação psíquica para obrigar alguém a fazer alguma coisa contrária a si, aos seus interesses e desejos, ao seu corpo e à sua consciência, causando-lhe danos profundos e irreparáveis". Portanto, pensar a conduta profissional é considerar a discriminação, estigma e violência estrutural 20 que desmoralizam.

Constatamos, como outros 1,5, que há uma assimetria na relação, parte de uma complexa rede de representações conflituosas com disparidades de classe, status, escolaridade, condições de vida etc. Quando o profissional, o cavalo batizado, maltrata - soltando grosserias, falando brutalmente ou tratando de modo ignorante-, o paciente é impotente para denunciá-lo abertamente. Protesta com a arma dos enfraquecidos 21 : uma crítica subjacente à hospitalização. Aprecia em pormenores essa relação, "investigando minuciosamente os menores gestos, interpreta as expressões mais sutis, avalia inclusive a distância que o separa do profissional" 22 (p. 40). Apesar de não declarar publicamente, o paciente realiza um julgamento ético de valor da conduta profissional, conforma a sua perspectiva do correto e do incorreto 19, dentro do mundo local moral 23.

A maioria das narrativas revelam histórias de descaso profissional: o segurança que impediu um marido de acompanhar o parto da esposa; o assistente que colocou a gestante em trabalho de parto numa maca no banheiro; a enfermeira que deixou uma mãe sangrando após o parto sem absorventes e calcinhas; o aprendiz que furou um paciente 16 vezes; a equipe que não informou as duas filhas sobre a morte da mãe e a faxineira que tirou os pedidos de salvação da imagem de Nossa Senhora. Ainda, vale a pena ressaltar que o paciente elogia e reconhece, pelo nome, quem lhe cuida bem. Portanto, a conduta de um profissional zeloso faz a diferença na experiência da hospitalização do seu paciente.

A viva voz do paciente é uma racionalidade leiga, uma crítica, uma confluência de problemas coletivos. Sua avaliação consegue ir além de estar "satisfeito" como numa Escala de Satisfação do Usuário 24,25. Ele é capaz de identificar a violência institucional sofrida na internação, interpretar os contatos, distinguir a qualidade dos cuidados, definir uma relação competente, desenvolver parâmetros para julgar quem cuida, prestigiar o profissional humano, reagir indignado contra os maus-tratos, buscar, em outros pacientes, sua fortaleza e mais.

Indiscutivelmente a competência humana do profissional é mais valorizada do que seu knowhow técnico. Não basta fazer uma ação mecanicamente correta, é necessário zelar a pessoa, executar com delicadeza, sem causar danos. São essas as tecnologias leves que Merhy 2,26 refere, pois o profissional deveria ser um operador do cuidado que gerencia multiprofissionais, acolhe, responsabiliza-se e cria vínculos.

Boff 10 corrobora a falta de competência humana do profissional. Carente de "cuidados essenciais" 9 (p.128), ele age tecnicamente, mas não Sabe Cuidar. O fundamental é a convivência, sujeito a sujeito: "intimidade, senti-las dentro, acolhê-las, respeitá-las, dar-lhes sossego e repouso" 9 (p. 95). Nosso paciente, portanto, não deixa dúvidas de como o profissional se tornaria um operador do cuidado: mudar radicalmente sua conduta, adquirindo competência em trocar afetos, conversar com pessoas e envolvê-lo nos cuidados. Começa com a inserção do sentimento no gesto e na fala clínica. Ele espera que o costume nordestino de "receber bem o visitante, oferecer um cafezinho e trocar abraços e beijos" se repita no hospital, com um trato igualmente carinhoso: troca de amor, meiguice, cafuné, olho no olho e palavra de conforto. É preciso criar sintonia, empatia e vínculo, compartilhando sua dor e alegria.

O mundo é feito a partir dos laços afetivos, sendo o sentimento a dinâmica básica do cuidado 9 . Maturana 27 (p. 23) compreende que a emoção e o amor são os grandes referenciais do agir humano; "o amor é fundante do social", e a doença surge da sua negação. Imaginamos, então, que, sem afetividade entre o profissional e o paciente, é enfraquecida a potência terapêutica da relação.

O paciente destaca a falta de um cuidado ético que honre sua dignidade humana, tratando-o 
como se fosse gente! Deseja uma conduta que integre a alteridade e o respeito. Portanto, é preciso cultivar, no profissional, uma atitude de generosidade humana, que respeite a diversidade cultural de cada povo, sem estigmatizar ou discriminar, estabelecendo uma relação terapêutica justa, equilibrada e madura 2,28 .

O paciente recrimina a linguagem técnica, objetiva, proposital e centrada na doença, que somente transmite informação. Requer conversar, “dar voltas com o outro (...) uma forma inclusivae extensiva de diálogo (...) um fluir na convivência, no entrelaçamento do linguagear e do emocionar" 29 (p. 80). Propõe uma comunicação que abarque códigos culturais do cotidiano nordestino: fala esclarecedora e uma conversa amiga, de peito e aberta e jogada fora. Exige uma conversa sincera, honesta e ética, independentemente da gravidade da notícia, seja um diagnóstico de câncer, a morte da mãe ou de seu bebê. Protesta contra o médico que engana as mulheres, recepcionista que enrola a gente e enfermeira que ilude. Teixeira 30 (p. 593) sugere um acolhimento dialogado: "o reconhecimento do outro como legítimo outro; de cada um como insuficiente e o sentido de uma situação fabricada pelo conjunto dos saberes presentes", fazendo emergir uma convergência das diversidades.

Embora $<15 \%$ dos informantes balizem a sua inclusão nas decisões terapêuticas, eles permanecem indignados. Por trás da gentil saudação, “o que você manda hoje, doutor?", encontramos um crítico do serviço público, um paciente-cidadão. Ele valoriza o profissional que sabe compartilhar o poder de decidir, e respeita sua autonomia; que sabe não só cuidar, mas também "empoderar" 31.

O discurso profissional predomina no hospital que investigamos. Insistir em falar pelo paciente, decidindo o que precisa ser feito sozinho, é um abuso de poder 32. Está longe de um compartilhamento dialógico, em que o paciente é sujeito, não apenas como "coadjuvante da decisão do como fazer, mas deve participar ativamente também das escolhas do que fazer" 33 (p. 696). É nesse palco de contradições, entretanto, que emerge a crítica leiga da internação, a etnoavaliação, provocando mudanças institucionais.

Não basta saber o grau de "satisfação" do paciente; é preciso "propiciar sua maior legitimi- dade e capital de poder no jogo intersubjetivo institucional" 34 (p. 28). Pouco adianta criar caixas de sugestões e ouvidorias se não for ampliado o direito de cidadania. Concordamos com Deslandes 35 na idéia que é prioridade o Estatuto de Pessoa e de Sujeito, pois valoriza e reconhece a pessoa como um indivíduo, com um ethos, uma cultura e um sujeito biográfico, singular e único.

\section{Reflexões finais}

A abordagem antropológica facilitou enxergar o protagonismo do paciente e demonstrar a sua valiosa crítica ou etnoavaliação da hospitalização. A pesquisa exigiu criar elos afetivos com os informantes, acompanhá-los de perto, durante todo o seu percurso no hospital, e penetrar o seu mundo moral local para que superassem o medo de reclamar do serviço. Somente com essa aproximação e confiança, conseguimos descobrir a riqueza oculta da sua vivência. Assim, amplia-se o olhar clínico para enxergar a pessoa no paciente, seus sentimentos, significados e julgamento ético de valor. Portanto, desvelar essa apreciação leiga é indispensável para humanizar o cuidado e garantir a cidadania.

Descobrimos a viva voz, não do "paciente" oprimido pelo poder institucional, mas do paciente-cidadão observador, reflexivo e crítico, capaz de avaliar minuciosamente o menor gesto e interpretar a expressão mais sutil do profissional, seja do cavalo batizado, seja do coração bondoso. É essa a voz legítima, comprometida com a defesa da vida, que poderá revolucionar a conduta profissional, remoralizar o paciente e humanizar o cuidado.

É necessário refletir, todavia, sobre a possibilidade de mudar as condutas profissionais inseridas em estruturas de iniqüidade. Há ainda, a necessidade de incorporar, na formação, além dos conhecimentos técnico-instrumentais, outras formas de saber: significados e sentidos da realidade do paciente-cidadão, sua cultura, emoções e condições de vida. Edificar uma nova relação terapêutica, não de dominação, mas de respeito, afeto e vínculo, é um grande desafio, entre muitos, para uma conduta profissional solidária e uma gestão ética a fim de construir o hospital humano. 


\section{Resumo}

Trata-se de pesquisa antropológica com o objetivo de revelar a apreciação do paciente-cidadão sobre a conduta profissional num hospital geral público, em Fortaleza, Ceará, Brasil. De janeiro a julho de 2005, foi acompanhado o percurso de 13 informantes-chaves durante a hospitalização, e sua narrativa da experiência, analisada. Constata-se que o paciente avalia os gestos e expressões dos cuidadores durante todo o percurso. Valoriza mais, no profissional, a competência humana de ser afetivo, de conversar e incluí-lo em decisões clínicas, do que sua habilidade técnica. Critica a atitude distante, fria e bruta, metaforicamente comparada a um cavalo batizado. Sugere uma ação profissional afetiva, empática e ética e uma comunicação clínica respaldada na fala, na conversa e no costume da vida cotidiana nordestina. Argumenta-se que essa voz legítima e crítica do paciente-cidadão oferece valiosas pistas para transformar a conduta profissional, remoralizar o paciente e construir o hospital humano no contexto de desigualdades sociais.

Relações Médico-Paciente; Humanização da Assistência; Assistência à Saúde

\section{Colaboradores}

O trabalho de campo, a redação e revisão final foram realizados por ambas as autoras.

\section{Agradecimentos}

Apoio do Conselho Nacional de Desenvolvimento Científico e Tecnológico (projeto no. 403744/2004-0: Hospital Humano: Etno-avaliação Centrada no Paciente e seus Sentidos, Significados e Experiências Vivida), Hospital Humano e da Fundação Cearense de Apoio ao Desenvolvimento Científico e Tecnológico.

\section{Referências}

1. Caprara A, Rodrigues J. A relação assimétrica médico-paciente: repensando o vínculo terapêutico. Ciênc Saúde Coletiva 2004; 9:139-46.

2. Merhy EE. Saúde: a cartografia do trabalho vivo. São Paulo: Editora Hucitec; 2002.

3. Bosi MLM, Affonso KC. Direito à saúde e participação popular: confrontando as perspectivas de profissionais e usuários da rede pública de serviços de saúde. In: Bosi MLM, Mercado-Martínez FJ, organizadores. Pesquisa qualitativa de serviços de saúde. Petrópolis: Editora Vozes; 2004. p. 451-79.

4. Kleinman A. Patients and healers in the context of culture: an exploration of borderland between Anthropology and Psychiatry. Berkeley: University of California Press; 1980.

5. Caprara A. Uma abordagem hermenêutica da relação saúde-doença. Cad Saúde Pública 2003; 19:923-31.
6. Ceccim RB. Educação permanente em saúde: desafio ambicioso e necessário. Interface Comun Saúde Educ 2005; 9:161-8.

7. Tardif M. Saberes docentes e formação profissional. Petrópolis: Editora Vozes; 2002.

8. Freire P. Pedagogia da autonomia: saberes necessários à prática educativa. São Paulo: Editora Paz e Terra; 2004.

9. Boff L. Saber cuidar: ética do humano - compaixão pela terra. Petrópolis: Editora Vozes; 1999.

10. Campos GWS. Humanização na saúde: um projeto em defesa da vida? Interface Comun Saúde Educ 2005; 9:389-406.

11. Núcleo Técnico da Política Nacional de Humanização, Secretaria Executiva, Ministério da Saúde. HumanizaSUS: política nacional de humanização. Documento base para gestores e trabalhadores do SUS. Brasília: Ministério da Saúde; 2005. 
12. BernalC.Cidade extrapola seus limites. http://adm. noolhar.com/servlet/opovo? event=ctdi_noticia (acessado em 10/Out/2006).

13. Geertz C. A interpretação das culturas. Rio de Janeiro: LTC Editora; 1989.

14. Kleinman A. The illness narratives: suffering, healing \& the human condition. New York: Basic Books; 1988.

15. Minayo MCS. O desafio do conhecimento: pesquisa qualitativa em saúde. São Paulo: ABRASCO; 2000.

16. Bardin L. Análise de Conteúdo. Lisboa: Edições 70; 2002.

17. Deslandes SF. Frágeis deuses: profissionais da emergência entre os danos da violência e a recriação da vida. Rio de Janeiro: Editora Fiocruz; 2002.

18. Goffman E. Stigma: notes on the management of spoiled identity. Englewood Cliffs: Prentice-Hall; 1963.

19. Chauí M. Convite à filosofia. São Paulo: Editora Ática; 1994.

20. Farmer P, Connors M, Simmons J. Women, poverty and AIDS: sex, drugs and structural violence. Monroe: Common Courage Press; 1996.

21. Scott JC. Domination and the arts of resistance: hidden transcripts. New Haven: Yale University Press; 1990.

22. Souza MLR. Os diferentes discursos na instituição hospitalar. Percurso 1999; 23:35-42.

23. Kleinman A. What really matters: living a moral life amidst uncertainty and danger. Oxford: University Press; 2006.

24. Uchimura KY, Bosi MLM. Qualidade e subjetividade na avaliação de programas e serviços em saúde. Cad Saúde Pública 2002; 18:1561-9.
25. Esperidião MA, Bomfim LA. Avaliação de satisfação de usuários: considerações teórico-conceituais. Cad Saúde Pública 2006; 22:1267-76.

26. Merhy EE. Um ensaio sobre o médico e suas valises tecnológicas: contribuições para compreender as reestruturações produtivas do setor saúde. Interface Comun Saúde Educ 1997; 6:109-16.

27. Maturana RH. Emoções e linguagem na educação e na política. Belo Horizonte: Universidade Federal de Minas Gerais; 1998.

28. Merhy EE. Em busca do tempo perdido: a micropolítica do trabalho vivo em saúde. In Merhy EE, Onoko R, organizadores. Agir em saúde: um desafio para o público. São Paulo: Editora Hucitec; 2002. p. 71-150.

29. Maturana RH. Da biologia e psicologia. Porto Alegre: Artes Médicas; 1998.

30. Teixeira RR. Humanização e atenção primária à saúde. Ciênc Saúde Coletiva 2005; 10:585-97.

31. Carvalho SR. As contribuições da promoção da saúde em relação à produção de sujeitos e a mudança social. Ciênc Saúde Coletiva 2004; 9:669-77.

32. Campos GWS. Saúde paidéia. São Paulo: Editora Hucitec; 2003.

33. Oliveira LA, Landroni, MAS, Kurokawa, Silva NE, Ayres JRCM. Humanização e cuidado: a experiência da equipe de um serviço de DST/Aids no Município de São Paulo. Ciênc Saúde Coletiva 2005; 10:689-98.

34. Deslandes S. A humanização e a construção política do lugar de sujeito no processo comunicacional. Ciênc Saúde Coletiva 2004; 9:25-9.

35. Deslandes SF. O Projeto ético-político da humanização: conceitos, métodos e identidade. Interface Comun Saúde Educ 2005; 9:401-3.

Recebido em 29/Set/2006

Versão final reapresentada em 26/Fev/2007

Aprovado em 19/Mar/2007 